\title{
O Ensino-Aprendizagem-Avaliação de Progressão Geométrica através da Resolução de Problemas na Licenciatura em Matemática
}

\author{
The Teaching-Learning-Evaluation of Geometric progression through \\ problem-solving in the Math under graduation
}

Matheus Metz Correa

Fabiane Cristina Höpner Noguti

\begin{abstract}
Resumo: Este artigo é recorte de uma dissertação que buscou investigar, na forma de um estudo de caso, quais as contribuições, no ensino e na aprendizagem de Progressão Geométrica, propiciada pela Metodologia de Ensino-Aprendizagem-Avaliação de Matemática através da Resolução de Problemas no Ensino Superior. Esta pesquisa teve como sujeitos licenciandos em Matemática da Universidade Federal de Santa Maria matriculados na disciplina de Resolução de Problemas. A coleta de dados ocorreu em sete encontros, no período de um mês, em que cada aula buscou contemplar um conceito específico da Progressão Geométrica. Utilizamos como instrumentos de coleta de dados: questionários, diários de campo, gravações de áudios e folha de resoluções dos registros dos alunos. De forma geral, essa metodologia possibilitou uma
\end{abstract} aprendizagem eficiente para os licenciandos em Matemática, os quais notaram que nem sempre há a necessidade de decorar fórmulas e teoremas durante a construção de conceitos e conteúdos matemáticos. Mestrando em Educação Matemática e Ensino de Física pela Universidade Federal de Santa Maria (UFSM). Rio Grande do Sul, Brasil.

Palavras-chave: Matemática Discreta. Ensino Superior. Ensino de Matemática.

Abstract: This article is sample of a dissertation that sought to investigate contributions, as a case study, in Teaching and Learning of geometric progression provided by the Teaching-Learning-Evaluation of Mathematics through Problem Solving in higher education. It had as its research subjects Mathematics undergraduate students from Universidade Federal de Santa Maria enrolled in the Problem solving class. Data collection was undertaken within seven meetings, during a month, in which each student sought to address a particular concept of Geometric progression. As data collection tools were used: questionnaires, field journals, audio recordings and the resolution sheets of the students' records. In general, this methodology allowed for an efficient learning by the Math undergraduates, in which they have noticed that not always it is needed to memorize formulas and theorems during the construction of mathematical concepts and contents.

Keywords: Discrete Mathematics. Higher Education. Mathematics teaching.

\section{Introdução}

Num primeiro momento, gostaríamos de evidenciar que este artigo é uma súmula de uma 
dissertação de mestrado ${ }^{1}$, do primeiro autor com orientação da segunda autora, do Programa de Pós-Graduação em Educação Matemática e Ensino de Física (PPGEMEF) da Universidade Federal de Santa Maria (UFSM).

Esta pesquisa teve por objetivo investigar quais as contribuições propiciadas no ensinoaprendizagem de licenciandos em Matemática ao associar o conteúdo de Progressão Geométrica (P.G.) com a Metodologia de Ensino-Aprendizagem-Avaliação de Matemática através da Resolução de Problemas (MEAAMRP), proposta por Onuchic e Allevato (2011).

A motivação para essa investigação se deu pelas percepções da necessidade que os alunos possuem em associar os conteúdos matemáticos com o seu cotidiano. Não eram raros questionamentos neste contexto, advindo dos alunos, em nossa prática docente como, por exemplo: "Professor, para que estou estudando isso?", "Professor, onde vou usar isso na minha vida?". Diante dessa perspectiva, e pela falta de hábito dos alunos em interpretar e resolver problemas, vimos a necessidade de realizar estudos no âmbito da pós-graduação, para, talvez, responder essas inquietações quanto aos processos de ensino de Matemática.

Dessa forma, num primeiro momento, optamos por dar continuidade a um estudo de Trabalho de Conclusão de Curso (CORREA, 2016), no qual foi desenvolvido um trabalho, na ótica de Polya (1995), sobre a Resolução de Problemas, a fim de auxiliar no ensino da Progressão Aritmética (P.A.). No entanto decidimos por dar ênfase a P.G. no âmbito do Ensino Médio e tendo 0 auxílio da MEAAMRP.

Contudo, ao contatarmos algumas escolas do município de Santa Maria (RS), notou-se que o ensino dos conteúdos de Sequências Numéricas, P.A. e P.G., estavam ocorrendo entre 0 primeiro e o segundo trimestre escolar, o que inviabilizava a aplicação dos problemas propostos para a pesquisa, pois não haveria tempo hábil entre a coleta de dados e a defesa da dissertação.

Diante desse cenário, preferimos realizar nossa investigação com os pilares do ensino de Matemática na Educação Básica - licenciandos em Matemática -, já que, conforme mapeamento realizado por Correa e Noguti (2019), pesquisas que tem enfoque nesses três eixos (MEAAMRP, P.G., Ensino Superior) simultaneamente, ainda são raras nos programas de pósgraduação do Brasil, em especial da Região Sul.

\footnotetext{
1 Dissertação a ser apresentada, em agosto de 2020, ao curso de Mestrado do PPGEMEF, como requisito parcial para obtenção do grau de Mestre em Educação Matemática, intitulada "Progressões Geométricas através da Resolução de Problemas: contribuições ao Licenciando em Matemática".
} 
Após emergir, mais profundamente, no universo da Resolução de Problemas e da MEEAAMRP, ao realizar alguns estudos (ALLEVATO e ONUCHIC, 2014; KRULIK e REYS, 1997; MORAIS e ONUCHIC, 2014; ONUCHIC e NOGUTI, 2014; PROENÇA, 2018, dentre outros) elaboramos como questão investigativa/problema para a nossa dissertação: "Quais contribuições a MEEAAMRP proporciona a licenciandos em Matemática no estudo da P.G.?".

A fim de respondê-la, organizamos nossa pesquisa em sete encontros tendo como sujeitos alunos, do curso noturno, matriculados na Disciplina Complementar de Graduação (DCG) intitulada de Resolução de Problemas² da UFSM.

Na medida em que nosso planejamento das aulas foi embasado nas 10 etapas propostas por Allevato e Onuchic (2014) para a MEAAMRP, enfatizamos que todos os encontros tiveram problemas geradores como ponto de partida para o ensino e a aprendizagem de P.G., de forma que fosse possibilitado, aos alunos, a construção de seus próprios conhecimentos ao buscar estratégias para resolvê-los.

Neste contexto, enfatizamos que seguiremos a seguinte definição de problema: "[...] um problema se configura na relação com o resolvedor, de tal modo que, se ele já conhece ou tem memorizados tais métodos de resolução ou não está interessado na atividade, não será para ele um problema" (ALLEVATO e ONUCHIC, 2014, p. 45).

Destacamos que cada encontro teve o propósito de evidenciar um conceito específico da P.G., a saber, sua definição, termos equidistantes, termo geral, soma finita, soma infinita, P.G. de segunda ordem e a geometria fractal associada à Progressão Geométrica. E, ainda, que os dados da pesquisa foram constituídos pelas soluções e estratégias apresentadas pelos alunos ao resolver os problemas, percebidos na folha de solução e nos áudios gravados, assim como dois questionários que foram aplicados no primeiro e último encontro. Na próxima seção daremos ênfase a MEAAMRP.

\section{A Metodologia de Ensino-Aprendizagem-Avaliação de Matemática Através da Resolução de Problema}

Estudos sobre a Resolução de Problemas no ensino de Matemática começaram a surgir

\footnotetext{
2 Reforçamos que a segunda autora era a professora regente da disciplina e o primeiro autor realizava sua docência orientada.
} 
a partir de 1945, quando George Polya escreveu o livro intitulado How to solve it: a new aspect of mathematical method, traduzido para o português como $A$ arte de Resolver Problemas. Nele, Polya propunha a resolução de problemas matemáticos por meio de quatro passos: compreensão do problema, estabelecimento de um plano, realização do plano e um retrospecto analisando e discutindo os encaminhamentos tomados para a resolução do problema.

Após esse "pontapé" dado por Polya em 1945, muitos outros autores começaram a pesquisar as contribuições da Resolução de Problemas no ensino da Matemática. Neste contexto, no Brasil, uma das pioneiras a se aprofundar nesse estudo foi Lourdes de La Rosa Onuchic, por volta de 1989.

Dentre as três concepções da Resolução de Problemas evidenciadas por Schroeder e Lester (1989), a saber, Ensino sobre a Resolução de Problemas, Ensino para a Resolução de Problemas e Ensino através da Resolução de problemas, Onuchic e seu Grupo de Trabalho e Estudos em Resolução de Problemas (GTERP), se propuseram a estudar mais fortemente a última.

Num primeiro período, definiam essa concepção como uma metodologia de ensinoaprendizagem, no entanto, após muitos estudos e pesquisas realizadas no GTERP, observaram que ela também propiciava o processo de avaliação, tanto no aluno quanto no professor. Dessa forma, passaram a denominá-la de Metodologia de Ensino-Aprendizagem-Avaliação de Matemática através da Resolução de Problemas. Nesta perspectiva, Onuchic e Allevato (2011) afirmam que

\begin{abstract}
ao considerar o Ensino-Aprendizagem-Avaliação, isto é, ao ter em mente um trabalho em que estes três elementos ocorrem simultaneamente, pretende-se que, enquanto 0 professor ensina, o aluno, como um participante ativo, aprenda, e que a avaliação se realize por ambos. 0 aluno analisa seus próprios métodos e soluções obtidas para os problemas, visando sempre à construção de conhecimento. Essa forma de trabalho do aluno é consequência de seu pensar matemático, levando-o a elaborar justificativas e a dar sentido ao que faz. De outro lado, o professor avalia o que está ocorrendo e os resultados do processo, com vistas a reorientar as práticas de sala de aula, quando necessário. Chamamos a esse processo de trabalho de uma forma Pós-Polya de ver a resolução de problemas. (p. 81).
\end{abstract}

Podemos notar assim que a avaliação possui grande relevância quando trabalhamos 0 ensino de Matemática por meio desta Metodologia uma vez que, segundo Pironel e Vallilo (2017), ela proporciona ao aluno intensificar seu desenvolvimento crítico e criativo, tornando-se um cidadão participativo no meio social, cultural e/ou profissional, podendo auxiliá-lo no sucesso da 
aprendizagem de Matemática. Neste contexto, os autores ainda reforçam que

a Metodologia de Ensino-Aprendizagem-Avaliação de Matemática através da Resolução de Problemas propõe que a avaliação deva acontecer durante todo 0 desenvolvimento da atividade proposta pelo professor. Por outro lado, o processo de avaliação deve ser iniciado antes mesmo do início da aula, quando o professor começa a elaborar o problema gerador ou decide adotar um problema existente. (PIRONEL e VALLILO, 2017, p. 281).

Nessa metodologia, o ponto de partida na aprendizagem do aluno é através de um problema gerador. É por meio dele que o discente irá pensar em estratégias, com auxílio de alguns conceitos prévios, a fim de construir seu próprio conhecimento, ou seja, o problema será 0 responsável por desencadear o processo ensino-aprendizagem dos alunos.

Ainda nesta visão, Allevato e Onuchic (2014) propõem que ao empregar essa abordagem metodológica durante suas aulas de Matemática, o professor poderá organizá-las e planejá-las seguindo dez etapas, esquematizadas na Figura 1, que foram sugeridas como orientadoras do processo de utilização da MEAAMRP.

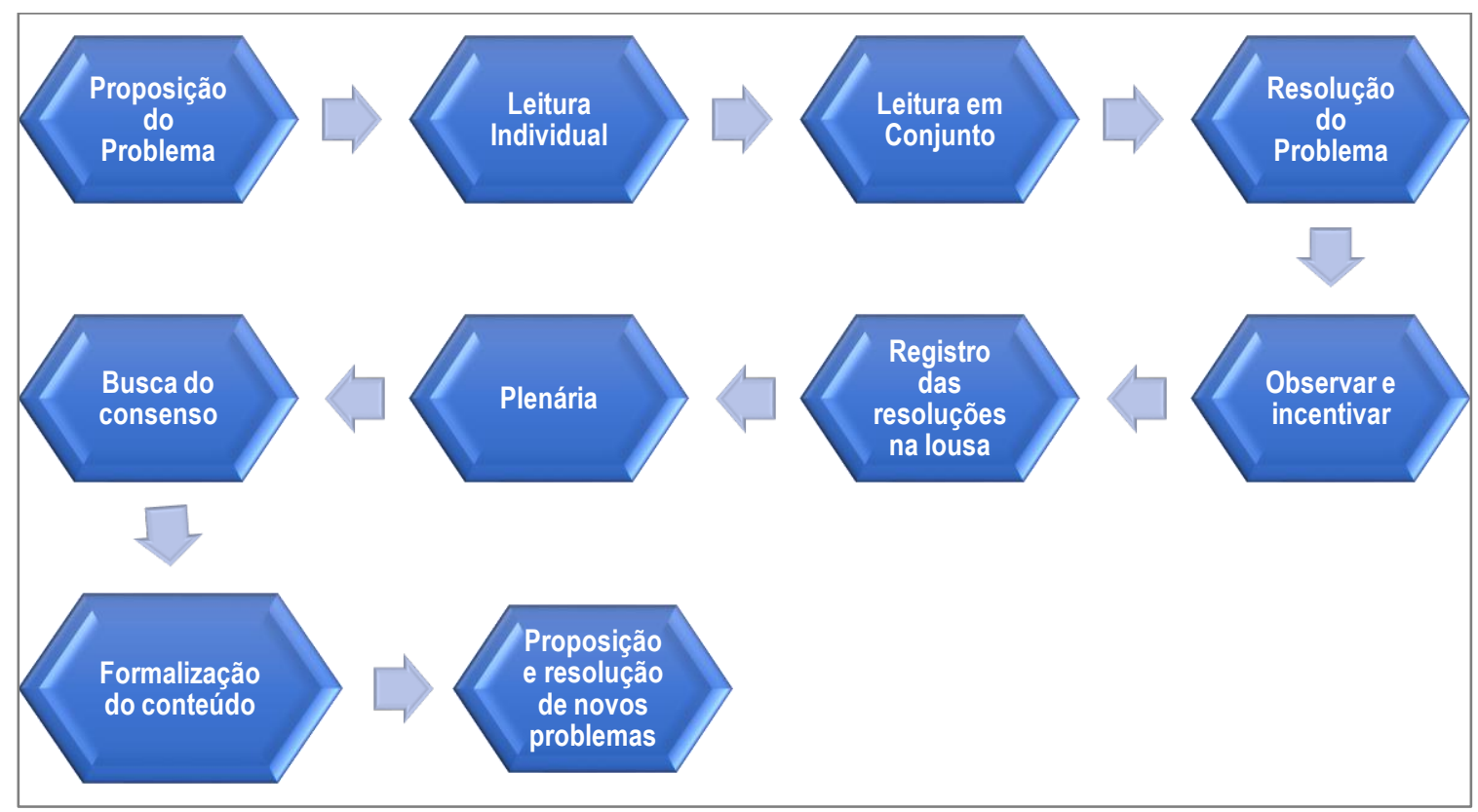

Figura 1: As dez etapas sugeridas para a MEAAMRP por Allevato e Onuchic (2014, p. 45)

Diferindo das outras concepções de Resolução de Problemas, nesta o aluno irá aprender um conceito matemático, desconhecido por ele, ao resolver o problema. Cabe, então, ao professor assumir um papel de mediador neste processo de aprendizagem do aluno, onde sua principal função, dentro dessa metodologia, é auxiliá-lo na descoberta de novos conhecimentos.

Cabe ressaltar que, por mais complicado que seja, o professor, ao utilizar essa 
metodologia, deve responder os questionamentos dos alunos por meio de uma nova pergunta, fazendo com que ele reflita e sozinho busque respondê-la, optando, ou não, por reformular suas estratégias tomadas para a resolução do problema. Nesse sentido, Allevato e Onuchic (2014) evidenciam que

recomendando fortemente esse trabalho em sala de aula, Van de Walle (2001) defende que a resolução de problemas deve ser a principal estratégia de ensino de Matemática. Ele chama a atenção para o fato de que esse trabalho começa sempre com os alunos, ao contrário de outras formas em que o ensino começa onde estão os professores, ignorando o que os alunos trazem consigo e para a sala de aula. A avaliação do crescimento dos alunos é feita, continuamente, durante a resolução do problema. Nesse sentido é que a avaliação se realiza integrada ao ensino e à aprendizagem, pois nessa metodologia o professor tem a oportunidade de perceber constantemente as condições e conhecimentos que os alunos possuem, ajudando-os durante o processo, bem como os próprios alunos se percebem e se ajudam, sendo eliminado o caráter sancionador das avaliações somativas (ditas tradicionais). (p. 47).

Nessa perspectiva, a MEAAMRP possibilita a interação entre alunos e professor na qual 0 docente permanece como mediador do processo ensino-aprendizagem e, ao participar das discussões entre os grupos dentro e fora da plenária, tem subsídios para realizar a avaliação como processo integrado das atividades realizadas.

\section{A Metodologia de Ensino-Aprendizagem-Avaliação de Matemática Através da Resolução de Problema no Ensino Superior}

Como evidenciado no mapeamento feito por Correa e Noguti (2019), as pesquisas de pósgraduação que trabalham esta Metodologia com enfoque no Ensino Superior ainda são poucas no Brasil, em especial na Região Sul. Esse fato ocorre tanto nos cursos de Licenciatura em Matemática quanto naqueles que possuem em suas ementas conteúdos de Matemática de nível superior como, por exemplo, as disciplinas de Variável Complexa e Equações Diferenciais Ordinais, presentes em alguns cursos de Engenharia.

No que tangencia a presença da Resolução de Problemas nos cursos de Licenciatura em Matemática, Rodrigues, Silva e Ferreira (2016) apud Ferreira, Silva e Martins (2017) realizaram um levantamento e evidenciaram que ela aparece em diversas ementas dos Projetos PolíticoPedagógicos destes cursos no Brasil. No entanto, a Resolução de Problemas não é vista como uma disciplina e, sim, como um recurso metodológico e/ou didático das disciplinas da área da Educação e da Matemática. 
Nesta perspectiva, a Licenciatura em Matemática da UFSM contrapõe, de certo modo, esse mapeamento realizado, visto que, tanto o curso diurno como o noturno, possuem, desde 2019 (diurno) e 2020 (noturno), a Resolução de Problemas como uma disciplina obrigatória da matriz curricular.

Com relação às pesquisas que utilizam a Resolução de Problemas no âmbito do Ensino Superior, tanto na formação inicial de professores quanto na abordagem em outros cursos, Ferreira, Silva e Martins (2017) evidenciam que elas vêm sendo trabalhadas em duas vertentes:

i) Com conteúdos da Educação Básica: Neste caso, a Resolução de Problemas é trabalhada com conteúdos do Ensino Fundamental ou do Ensino Médio. Em geral, esses conteúdos são abordados em disciplinas de Matemática Elementar, dadas no início de Graduação (Licenciatura ou outros), ou em outras disciplinas como Didática, Estágio Supervisionado, etc.

ii) Matemática Superior: Nesta abordagem, a Resolução de Problemas é trabalhada em disciplinas de nível superior, como Cálculo Diferencial e Integral, Álgebra Linear, Álgebra Abstrata, Análise Real, Equações Diferenciais, etc. (p. 191).

Reforçamos, de forma específica, que nossa pesquisa abarca os aspectos apontados no item (i) uma vez que a P.G. é (ou deveria ser) um conteúdo, originalmente, visto no Ensino Médio. Com ela pretendeu-se proporcionar, aos futuros licenciados em Matemática da UFSM, uma nova abordagem metodológica para que, talvez, durante sua futura prática docente, possam ensiná-la com o auxílio da MEAAMRP.

Ainda neste universo, evidenciamos o que Ferreira, Silva e Martins (2017) consideram quanto ao uso desta Metodologia para o ensino de conteúdos da Educação Básica nas Licenciaturas em Matemática:

É notória uma presença mais acentuada da metodologia da RP em cursos de Licenciatura em Matemática com o uso de conteúdos da Educação Básica abordando conteúdos da Matemática Elementar. Observamos que as pesquisas convergem para a preocupação em formar um professor reflexivo e preparado para atuar na docência, mesmo com o uso de conteúdos básicos de Matemática. Nesse movimento de repensar a prática docente, abordando conteúdos básicos de forma diferenciada na Licenciatura em Matemática, criam-se novos caminhos, novas possibilidades em Educação Matemática, sempre priorizando o aluno como protagonista do seu aprendizado. E as pesquisas têm mostrado que a Metodologia de EnsinoAprendizagem-Avaliação de Matemática através da Resolução de Problemas tem se apresentado como um caminho viável para atingir esses propósitos. (FERREIRA, SILVA e MARTINS, 2017, p. 215).

Dessa forma, nossa pesquisa, também, busca instigar futuros pesquisadores a verificar quais contribuições que essa Metodologia diferenciada poderá propiciar no processo de Ensino- 
Aprendizagem-Avaliação dos alunos do Ensino Superior em outros conteúdos matemáticos.

\section{Percursos metodológicos e contextualização da pesquisa}

Quanto à abordagem metodológica seguida pela nossa pesquisa, podemos dizer que, baseado em Lüdke e André (2015), ela possuiu cunho qualitativo uma vez que nos preocupamos em dar significados valorativos ao fazer a análise dos dados da pesquisa, buscando destacar, sempre que possível, os pontos de vista dos alunos.

Com relação aos procedimentos técnicos, aferimos nossa pesquisa como sendo um estudo de caso de natureza empírica. Neste sentido, Lüdke e André (2015) destacam algumas características presentes nesse tipo de pesquisa. Para elas, o estudo de caso visa a um descobrimento; realça a interpretação naquela situação; busca retratar a realidade, daquele caso, de maneira integral e profunda; usa uma variedade de fontes de interesse e/ou informação; revela uma experiência substituta permitindo conjecturas naturalísticas; e procura representar os díspares e às vezes contraditórios pontos de vista presentes numa situação social.

Dessa forma, nosso estudo de caso, de modo especifico, procurou analisar de que maneira os alunos do curso de Licenciatura em Matemática, período noturno, da UFSM, matriculados na DCG — Resolução de Problemas resolveram os problemas propostos sobre P.G., na perspectiva da MEAAMRP, com o propósito de identificar quais foram os métodos utilizados, bem como, elucidar seus pontos de vista na tentativa de resolvê-los.

As pesquisas desse tipo carecem de distintas fontes de informação a fim de apurar os resultados e apontar coesão diante da análise dos dados coletados. Nesse contexto, evidenciamos que os instrumentos de coletas de dados utilizados em nossa investigação foram dois questionários (Inicial e Final), diários de campos do pesquisador, áudios, fotografias, folhas de registros das soluções dos problemas apresentadas pelos alunos e análise de documentos iniciais.

Quanto à aplicação dos questionários, destacamos que ambos foram importantes, uma vez que nos permitiram ter uma visão panorâmica do público da nossa pesquisa. 0 questionário inicial buscou identificar o perfil socioeconômico dos alunos, assim como conhecer, superficialmente, sua noção sobre a Resolução de Problemas e P.G., em nível médio e/ou superior. O final, que possuiu questões abertas, almejou verificar quais foram as contribuições, na percepção dos alunos, ao trabalhar a P.G. por meio da MEAAMRP e, também, suas concepções 
sobre o trabalho em grupo durante as resoluções dos problemas.

Ainda nesse contexto, ao final de cada encontro elaborávamos um diário de campo com o objetivo de apontar o máximo possível de informações relevantes alcançadas durante aquele dia. Esse diário de campo foi fundamental nas análises qualitativas, pois ele permitiu destacar as percepções observadas pelo pesquisador durante a realização da pesquisa.

Por fim, a folha de registros das soluções dos problemas apresentadas pelos alunos foi parte primordial da análise da pesquisa, na medida em que nelas ficaram registrados os encaminhamentos matemáticos seguidos pelos grupos para resolvê-los, e, ainda, por meio dos áudios conseguimos retratar, mais fidedignamente, o ponto de vista dos sujeitos ao resolver determinado problema, uma vez que apenas com a observação poderíamos deixar de evidenciar algum aspecto importante que passou despercebido.

Desta forma, essa escolha por uma diversidade de instrumentos corrobora com o que Yin (2001) afirma. Segundo ele, durante a coleta de dados, as pesquisas deste tipo devem ter três princípios básicos: utilizar distintas fontes de evidência, criar um banco de dados para o estudo de caso e manter o encadeamento das evidências.

Neste sentido "no capítulo de discussões dos resultados, a voz predominante é a voz dos dados que, inicialmente, tem uma força muito grande. Aparecem aí as vozes dos sujeitos da pesquisa e, implícita ou explicitamente, outras vozes como as mídias utilizadas" (BORBA, ALMEIDA e GRACIAS, 2018, p. 80).

Como reforçado anteriormente, os encontros ocorreram durante a DCG — Resolução de Problemas. A disciplina era estruturada em 30 aulas de duas horas, totalizando uma carga horária de 60 horas. Eles ocorreram todas às segundas-feiras, das $19 \mathrm{~h}$ às $21 \mathrm{~h}$, e às quartas-feiras, das $21 \mathrm{~h}$ às $23 \mathrm{~h}$, durante 0 semestre letivo.

No entanto, cabe realçar que a coleta de dados da pesquisa não aconteceu em todas as aulas, resguardamos sete encontros com 0 intuito de realizar as atividades relacionadas a ela, organizadas e cumpridas conforme Quadro 1.

A definição por esse quantitativo de encontros ocorreu devido ao conteúdo programático da ementa da disciplina e, também, pelo limite de horas-aulas permitido para a docência orientada. 
Quadro 1: Organização dos encontros da pesquisa

\begin{tabular}{|c|c|}
\hline Encontro & Conteúdo da P.G. programado \\
\hline Aula 23 & Conceitos iniciais da P.G. \\
\hline Aula 24 & Termos Equidistantes \\
\hline Aula 25 & Termo Geral \\
\hline Aula 26 & Soma Finita \\
\hline Aula 27 & Soma Infinita \\
\hline Aula 28 & P.G. de Segunda Ordem \\
\hline Aula 29 & Geometria Fractal associada à P.G. \\
\hline
\end{tabular}

Fonte: Elaboração dos Autores

Os sujeitos da nossa pesquisa foram seis alunos matriculados na DCG - Resolução de Problemas. Alertamos que, originalmente, o total de alunos era 13 , no entanto apenas sete frequentavam as aulas regularmente, e um deles foi reprovado ao alcançar o número máximo de faltas permitidas (7). Como constatado no questionário inicial, os sujeitos advinham de semestres e turnos distintos, sendo que dois deles estavam concluindo a Licenciatura em Matemática naquele ano.

Como medida de não identificá-los, durante a entrega do Termo de Consentimento Livre e Esclarecido ${ }^{3}$ (TCLE), recomendamos que escolhessem um codinome que lhes acompanharia durante e posteriormente a realização das atividades. Por conseguinte, eles optaram pelos seguintes "apelidos": Baraka, Fermat, Joaquim, Beija-Flor, Marcelle e Joana, que serão utilizados, ao nos referirmos a eles.

Os problemas escolhidos para os encontros buscaram contemplar as dez etapas sugeridas por Allevato e Onuchic (2014) ao trabalhar com a MEAAMRP. Nesta visão, optamos por questões que possibilitassem, o máximo possível, seguir a sequência proposta pelas autoras e que admitissem, aos alunos, uma busca e formulação de ideias, por si mesmo, para a resolução do problema.

O objetivo central desses encontros foi, ao finalizarmos as resoluções dos problemas, formalizar os tópicos da P.G. pretendidos, por mais que alguns deles já os haviam estudado no

\footnotetext{
${ }_{3}^{3}$ Projeto aprovado no Comitê de Ética em Pesquisa (CEP) da UFSM sob o número 27358119.0.0000.5346.
} 
Ensino Médio. Com relação à escolha do problema, Pironel e Vallilo (2017) evidenciam que

\begin{abstract}
quando 0 professor decide que o problema pode ser um ponto de partida para a construção de um novo conhecimento para o aluno, ele precisa se debruçar sobre a tarefa da escolha ou da elaboração de uma atividade que esteja alicerçada num problema ou numa situação-problema, cuja resolução seja o fio condutor da aprendizagem de determinado conteúdo pelo aluno. Nesse sentido, os objetivos almejados devem estar alinhados com os objetivos curriculares propostos para determinado conteúdo matemático [...]. O problema deve ser escolhido pelo professor levando em consideração o conteúdo matemático que ele procura trabalhar com seus alunos e, além disso, pensando nos conteúdos que os alunos já dominam para resolver o problema. (p. 285).
\end{abstract}

Pelo fato de os sujeitos da pesquisa serem alunos do Ensino Superior, optamos por problemas que suas resoluções eram, relativamente, mais complexas que as habitualmente vistas no Ensino Médio. Neste contexto, priorizamos por selecioná-los em bancos de questões de seleções de ingresso em diversas universidades brasileiras e nas forças armadas.

Ainda, optamos, também, por pesquisá-los nos bancos de provas do Exame Nacional do Ensino Médio (ENEM), de diferentes anos, e da Olimpíada Brasileira de Matemática das Escolas Públicas (OBMEP), devido a seus níveis de complexidade na resolução de algumas questões.

Ressaltamos que em dois dos encontros buscamos por associar a MEAAMRP com outros recursos didáticos a fim de que os alunos tivessem uma possibilidade de aprendizagem que aprimorassem de novas abordagens de ensino para sua futura prática docente.

No primeiro encontro utilizamos do material manipulativo Torre de Hanói, para o qual um problema foi selecionado com o intuito de que pudessem manipulá-lo a fim de determinar a sua solução, conforme observado na Figura 2. Já no último encontro usamos algumas ferramentas disponível no GeoGebra com a finalidade de mostrar-lhes, visualmente, como a Geometria Fractal se comportava ao associá-la à Progressão Geométrica.

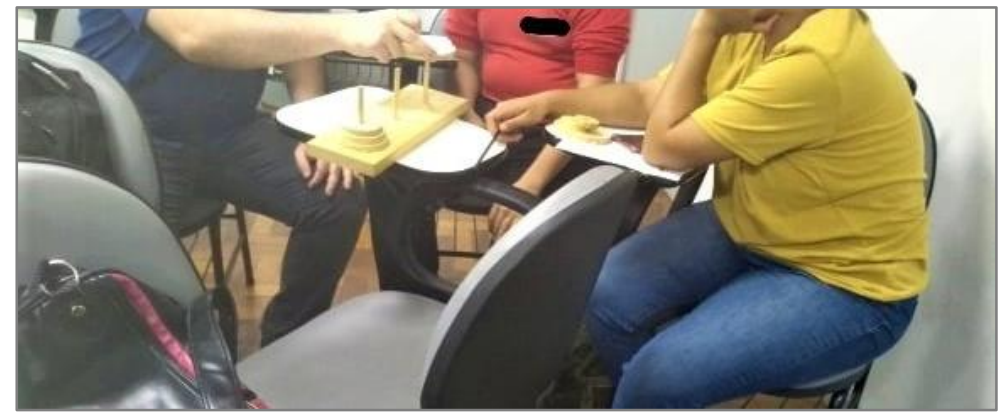

Figura 2: Alunos manipulando a Torre de Hanói (Acervo da Pesquisa)

Na próxima seção, mostramos e debateremos sobre os encaminhamentos seguidos pelos 
grupos ao resolverem alguns problemas do segundo, terceiro, quinto e sétimo encontros, buscando identificar suas resoluções e semelhanças assim como evidenciar as dificuldades percebidas, tanto pelos alunos quanto pelo professor, ao solucioná-los. Dessa forma, pretendemos elucidar as contribuições propiciadas pela MEAAMRP aos processos de ensino e de aprendizagem da P.G. envolvendo licenciandos em Matemática.

\section{Diagnóstico de alguns encontros}

Buscando seguir as orientações propostas por Allevato e Onuchic (2014), para o trabalho com a MEAAMRP, selecionamos e/ou adaptamos três problemas, para cada encontro — dois para a aula e um extraclasse - desencadeadores dos processos de ensino e de aprendizagem dos alunos.

Uma vez que já adotávamos, na DCG, o estudo da Resolução de Problema na ótica da MEAAMRP, seguindo as dez etapas, os alunos já estavam cientes da necessidade de ilustrar, no quadro, as suas estratégias pensadas, para a resolução do problema, durante a plenária, conforme podemos ilustrar na Figura 3.

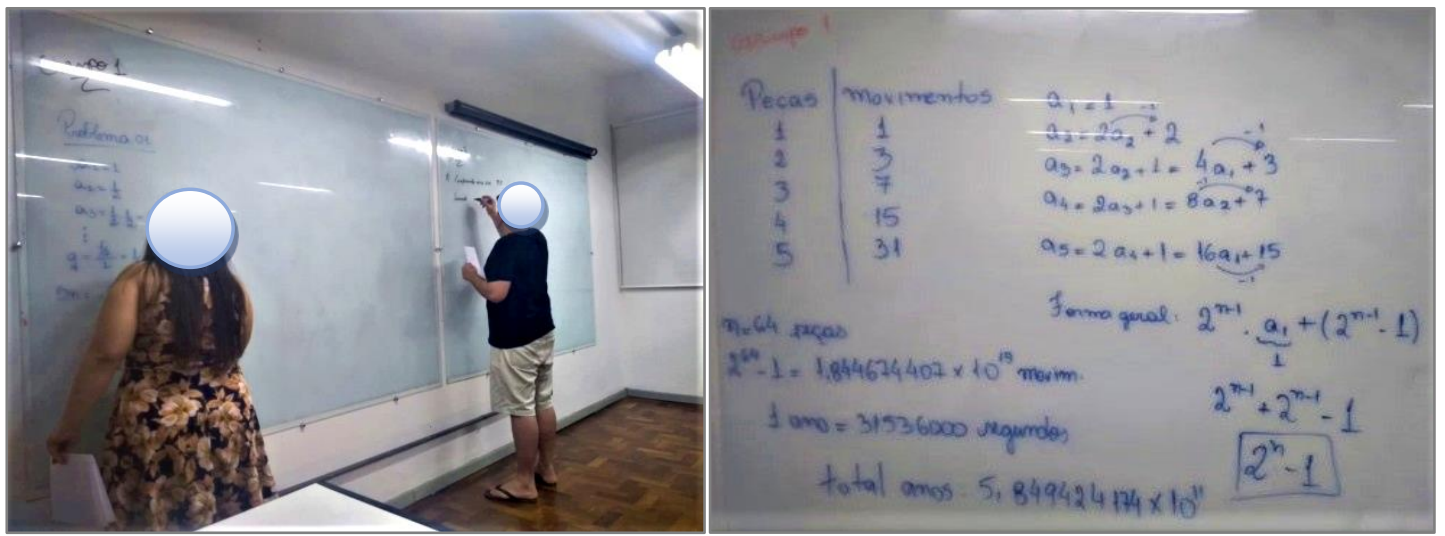

Figura 3: Momento da Plenária (Acervo da Pesquisa)

Vale ressaltar que, nos primeiros encontros, os alunos tinham bastante dificuldade em desenvolver um trabalho cooperativo e colaborativo, processo essencial nessa metodologia, uma vez que eles ainda possuíam receio de socializar seus pensamentos, com os colegas e com os professores, durante a resolução do problema. Não foi raro momentos de silêncio durante os encontros, apesar dos pesquisadores sempre reforçarem a necessidade de um diálogo no grupo.

Talvez esse fato tenha ocorrido por se sentirem inseguros em explanar suas ideias com receio de estarem seguindo um caminho errôneo e serem criticados por alguma das partes (alunos 
e/ou professores). Nos encontros finais isso foi se modificando, pois ficaram mais íntimos desse processo, notando que o diálogo nessa metodologia era necessário e que não haveria nenhum tipo de repreensão dos membros da pesquisa.

Destacaremos, neste espaço, quatro problemas trabalhados em alguns dos encontros 2, 3, 5 e 7 -, apresentando como ocorreu a sua dinâmica, qual era o problema gerador, os encaminhamentos seguidos pelos grupos para sua resolução e apontamentos que achamos pertinentes a serem evidenciados.

O Problema Extraclasse do $2^{\circ}$ encontro, Figura 4, objetivava estimular os alunos a relembrar e/ou definir a propriedade dos Termos Equidistantes de uma P.G., que muitas vezes não é vista no Ensino Médio.

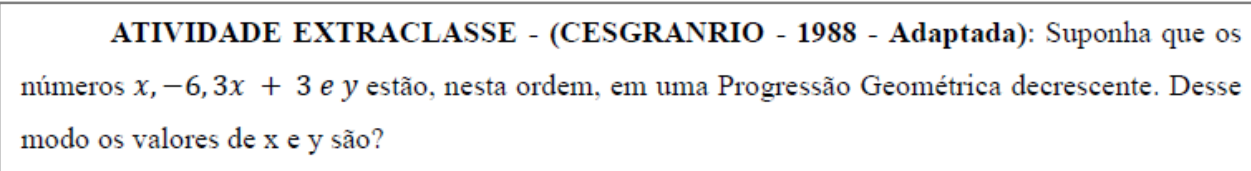

Figura 4: Atividade Extraclasse do $2^{\circ}$ encontro (Acervo da Pesquisa)

Neste dia, estavam presentes quatro alunos - Baraka, Fermat, Joaquim e Joana -, formando assim duas duplas. Como esta atividade era bastante similar a problemas por eles conhecidos $^{4}$, os grupos tiveram certa facilidade de resolvê-lo, pois partiram de uma mesma estratégia. Durante a leitura do problema, individual e em grupo, perceberam a existência de duas incógnitas em seu enunciado, o que, segundo eles, tornava-o mais complexo. Na Figura 5, encontram-se suas resoluções.

Como podemos observar, a maneira de resolver o problema, por parte dos grupos, foi bastante similar. Ambos optaram por utilizar a definição de razão para dar início à resolução. 0 que diferiu suas soluções foram os encaminhamentos finais. Uma vez que o Grupo 1 escolheu por não definir um valor para a incógnita $y$, mas sim determinar, diretamente, $04^{\circ}$ termo utilizando a definição de Termo Geral da Progressão Geométrica.

Já o Grupo 2 desenvolveu a resolução do problema por meio de uma relação para $y$, conhecida por meio da definição de razão, e após encontrar o valor de $x$, determina-o mediante essa relação. Ou seja, eles se preocuparam em definir o valor de $y$ que correspondia ao $a_{4}$.

\footnotetext{
4 Para conhecimento de todos os problemas sugerimos a leitura da dissertação de mestrado do primeiro autor.
} 


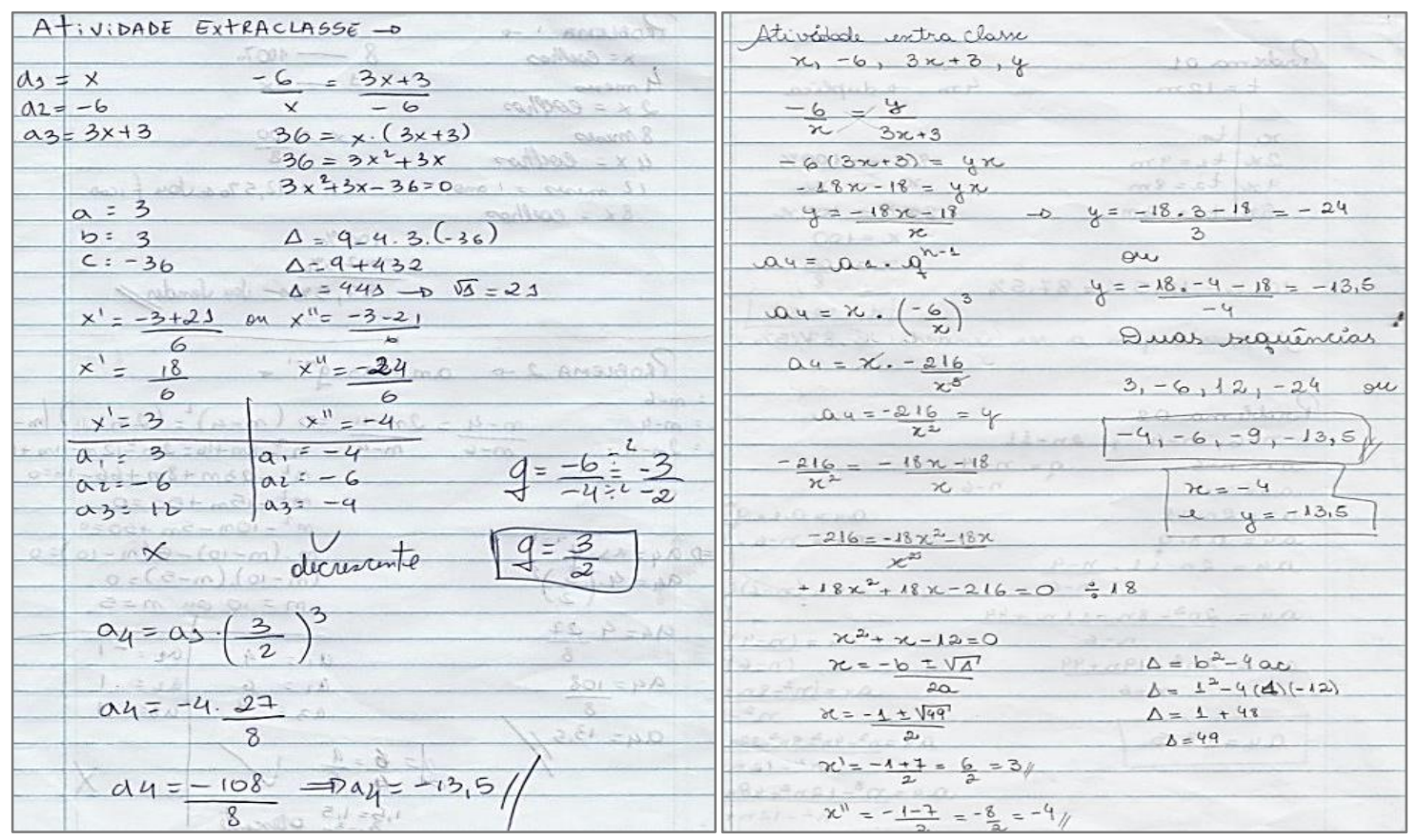

Figura 5: Resoluções apresentadas pelos grupos (Acervo da Pesquisa)

Durante a plenária, questionamos os alunos se não existiria uma maneira mais prática de resolver o problema, fazendo uso de alguma propriedade da Progressão Geométrica. $O$ aluno Fermat, então, recordou dos Termos Equidistantes da P.G. e comentou que por meio dela a solução do problema seria mais rápida e fácil.

Comentamos aos grupos que havíamos resolvido os problemas a partir de três estratégias distintas, a saber, por meio da definição da P.G, utilizando a relação da razão, e por meio dos termos equidistantes, deixando explicitado que nem todos os problemas possuem um único caminho para resolvê-los.

Evidenciamos que no terceiro encontro estavam presentes apenas três alunos - Baraka, Fermat e Joana -, dessa forma, eles foram organizados em apenas um grupo de trabalho. 0 Problema 2 deste encontro, Figura 6, visava aprofundar suas aprendizagens quanto ao conceito de Termo Geral da Progressão Geométrica. 
PROBLEMA 2 - (VUNESP - 2003 - ADAPTADO): Várias tábuas iguais estão em uma madeireira. A espessura de cada tábua é $0,5 \mathrm{~cm}$. Forma-se uma pilha de tábuas colocando-se uma tábua na primeira vez e, em cada uma das vezes seguintes, tantas quantas já estejam na pilha.

(1)

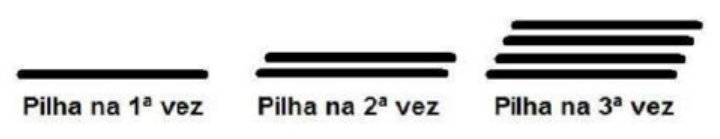

Ao final de nove dessas operações:

a) quantas tábuas terá a pilha?

b) qual será a altura, em metros, da pilha?

c) Após quantos empilhamentos a altura, desta pilha, de tábuas será de $20,48 \mathrm{~m}$ ?

d) Mostre que $\forall n \in N$, a altura da pilha, em $\mathrm{cm}$, é igual à metade da quantidade de tábuas empilhadas?

Figura 6: Segundo problema do $3^{\circ}$ encontro (Acervo da Pesquisa)

Nele foi solicitado, além de conjecturas, a prova/demonstração de uma afirmação. Este fato ocorreu porque nossos sujeitos da pesquisa eram alunos de Ensino Superior da Licenciatura em Matemática, na qual a demonstração de proposições se faz necessária em diversas disciplinas. Neste sentido, Fiorentini e Oliveira (2010) evidenciam que

\begin{abstract}
a demonstração tem um papel central na produção do conhecimento matemático. Ela faz parte da investigação matemática. A demonstração nada mais é do que a tentativa do matemático justificar ou provar, com recursos lógico-matemáticos, que uma conjetura é válida. $O$ professor precisa saber que uma demonstração não deve ser, necessariamente, sempre formal e fazer parte de um sistema axiomático. A exigência de rigor formal pode ser danosa, impedindo que o estudante (e, aqui, incluímos o futuro professor) possa fruir, explorar e experienciar o processo de criação da matemática. Há diversos modos de construir provas ou justificativas para as conjeturas. Alunos do ensino fundamental podem fazer pequenas demonstrações - isto é, construir justificativas e argumentações não formais e que podem ser aceitas como válidas no contexto de uma comunidade de aprendizagem matemática de sala de aula do Ensino Fundamental. Mas não é suficiente o futuro professor conhecer teoricamente, ou a partir da didática da matemática, como podem ser e funcionar as demonstrações em um ambiente exploratório-investigativo com a matemática. É preciso que ele possa experienciar o processo de exploração e investigação nas disciplinas matemáticas da licenciatura, tais como: teoria dos números, cálculo diferencial e integral, álgebra, análise, geometria, fractais, teoria dos grafos etc. (p. 925).
\end{abstract}

Numa primeira leitura do problema, 0 aluno Fermat acreditava que a sequência formada era uma P.A., pois, segundo ele, as tábuas estavam sendo acrescidas e não multiplicadas. Joana o convenceu, a partir de alguns diálogos, que a pilha de tábuas multiplicava-se a cada novo empilhamento, uma vez que a quantidade de tábuas adicionada na etapa seguinte era a mesma da pilha anterior. Assim o grupo chegou ao consenso que o problema era realmente uma Progressão Geométrica.

No item a, o grupo conjecturou uma relação, entre o número de tábuas e o empilhamento, 
sem utilizar o conceito de Termo Geral da Progressão Geométrica. Eles deduziram, termo a termo, a lógica relativa à quantidade de tábuas em cada pilha. Como cada termo possuía uma potência de 2, determinaram, corretamente, que no nono empilhamento haveria 256 tábuas.

Com relação à letra $b$, o grupo percebeu, com certa facilidade, que para definir a altura do empilhamento bastava multiplicar o valor encontrado no item a pela espessura de cada tábua que era definida por $0,5 \mathrm{~cm}$. Desta forma, deliberaram que a altura do $9^{\circ}$ empilhamento era de $1,28 \mathrm{~m}$ ou $128 \mathrm{~cm}$.

Na letra $c$, também fizeram uso da relação definida no item a uma vez que a altura do empilhamento se deu pela multiplicação da quantidade de pilhas pela espessura. Assim, generalizam que ela poderia ser encontrada pela relação $h=2^{n-2}$. E ainda, quando a altura do empilhamento tiver $20,48 \mathrm{~m}$ a quantidade de tábuas será 13. Na Figura 7, apresentamos a resolução dada pelo grupo nos itens $a, b$ e $c$.

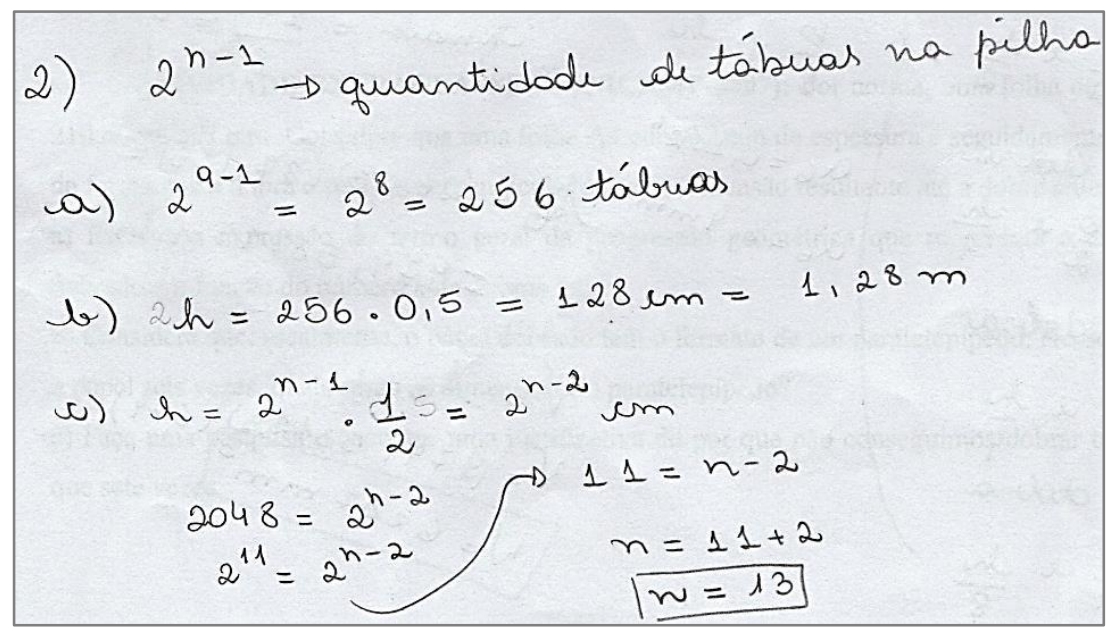

Figura 7: Resolução do grupo para os itens $a, b$ e $c$ (Acervo da Pesquisa)

Com referência ao item $d$, o grupo optou, em um primeiro momento, por testar, numericamente cada termo a fim de identificar qual era o padrão que a afirmação estava se comportando, para, posteriormente, concluí-la algebricamente. O grupo "demonstrou" esta afirmação, conforme Figura 8, mais informalmente, sem o uso de ferramentas comumente utilizadas em provas matemáticas, como, por exemplo, o Princípio da Indução Matemática (P.I.M) e a Demonstração por Absurdo. Para isso, optam por empregar relações definidas nos itens a e c. 


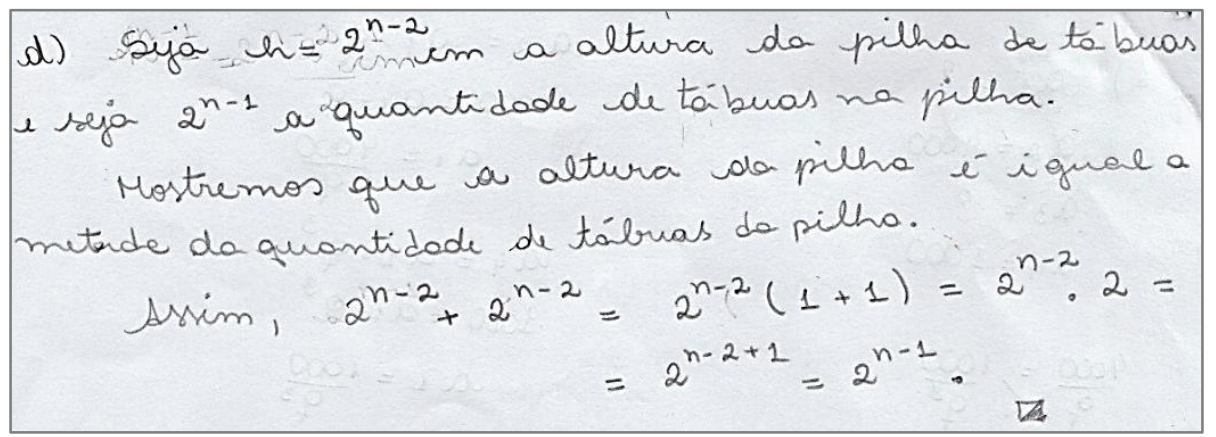

Figura 8: Resolução do grupo para o item d (Acervo da Pesquisa)

No quinto encontro estavam presentes cinco alunos, a saber, Beija-Flor, Fermat, Joaquim, Joana e Baraka, desta forma os dispomos em um trio e uma dupla. O Problema 1 deste encontro, Figura 9, possibilitou desenvolver um trabalho no qual os alunos pudessem observar como a soma infinita se comportava em uma P.G., e, para resolvê-lo, era necessário o conhecimento de conceitos prévios envolvendo semicírculos.

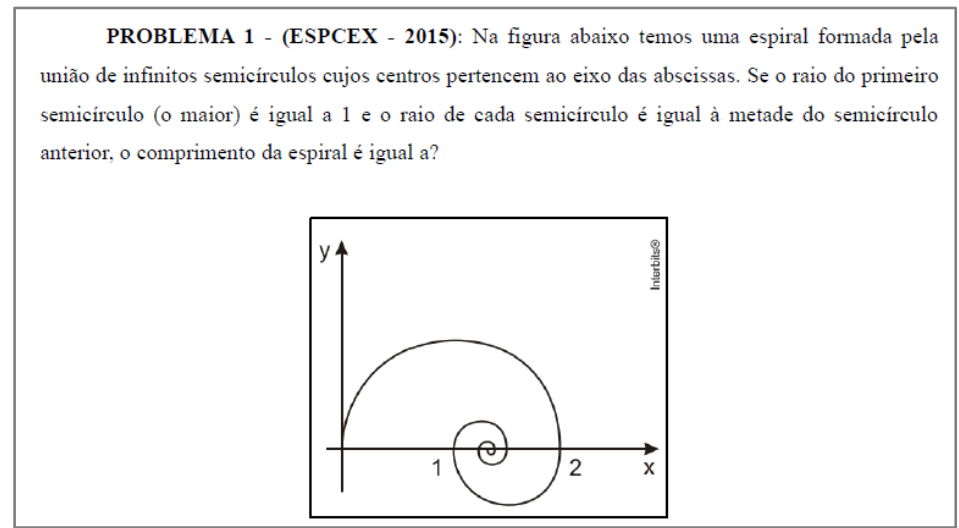

Figura 9: Problema 1 do quinto encontro (Acervo da Pesquisa)

Durante a leitura desse problema, um dos grupos levantou um apontamento bem pertinente. Para eles, o enunciado não deixava claro se o raio seguinte era representado pela metade do raio anterior ou pelo comprimento do semicírculo anterior. Argumentamos que, originalmente, o problema considera como sendo a metade do raio anterior e, também, acreditamos que a lógica do problema era nesse sentido. Assim, orientamos que os grupos seguissem por meio dessa estratégia.

De todos os problemas propostos naquele encontro, este foi o que os alunos tiveram mais facilidade para resolver uma vez que, para isto, os grupos, apenas, deveriam identificar que a sequência de semicírculos que formava a espiral estava se comportando como uma P.G. de razão $\frac{1}{2}$. Como eles já possuíam certo conhecimento de como determinar a soma infinita de uma P.G., apenas foi necessário que tivessem ciência de dois fatores: a sua razão e buscar uma estratégia 
que possibilitasse definir quais eram os comprimentos dos semicírculos que formavam a espiral.

O que diferenciou, minimamente, as resoluções dos grupos foram as poucas estratégias distintas adotadas por eles. 0 Grupo 1, optou por seguir sua resolução baseado na soma dos infinitos comprimentos dos semicírculos que originavam a espiral.

Para isso, utilizaram, simultaneamente, a ideia de somatório e a fórmula que determinava esses comprimentos $(\mathrm{C}=\pi \mathrm{r})$, na qual eles notaram que o raio do comprimento "final" se dava pela adição dos valores de todos os raios dos semicírculos, e, para determinar isso, utilizaram a soma infinita da Progressão Geométrica. Vale apontar que, durante a resolução do problema, o aluno Fermat assinalou uma relação bem interessante observada por ele: o raio seguinte era 0 diâmetro do semicírculo anterior.

Já o Grupo 2 não utilizou dessas mesmas estratégias, optam, num primeiro momento, por descobrir qual era a razão da P.G. formada pelos raios para, assim, definir sua soma infinita.

O que ficou discutível na sua resolução foi a forma que determinaram o comprimento da espiral, uma vez que o grupo definiu-o como sendo 2, porém esqueceram que, este comprimento, trata-se da soma dos valores dos infinitos semicírculos, para os quais suas medidas seriam calculadas por $\pi \mathrm{r}$, sendo que, neste caso, a solução mais correta para o problema seria $2 \pi \mathrm{r}$. $\mathrm{Na}$ Figura 10 encontram-se as soluções de ambos os grupos.

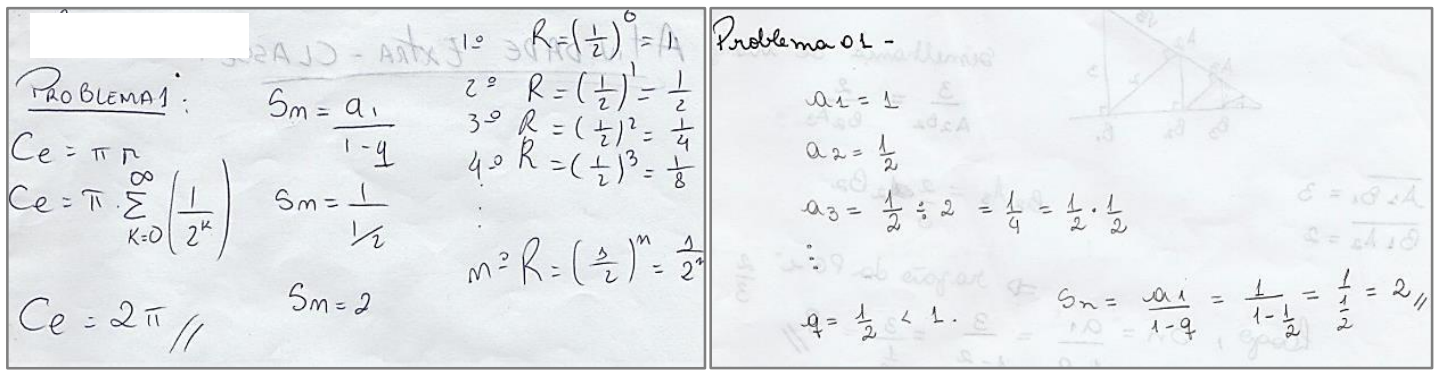

Figura 10: Resoluções dos grupos (Acervo da Pesquisa)

Quanto à discussão desse problema, na plenária, apontamos e questionamos, aos grupos, o porquê da diferença de resposta encontrada por eles, na qual ficou constatado que o Grupo 2, não definiu o comprimento da espiral representado pela soma dos valores dos semicírculos, na medida em que eles apenas calcularam o somatório dos valores de todos os raios, e não era isso que o problema solicitava. Houve assim alguns equívocos na interpretação do problema por parte do Grupo 2.

Com o Problema Extraclasse do encontro 7, Figura 11, nosso intuito era mostrar, aos 
alunos, que os fractais não estavam conexos apenas ao Termo Geral da P.G. ${ }^{5}$, mas também a sua soma infinita. Para isso, recorremos à uma questão originalmente desenvolvida pela Universidade Federal do Rio de Janeiro (UFRJ).

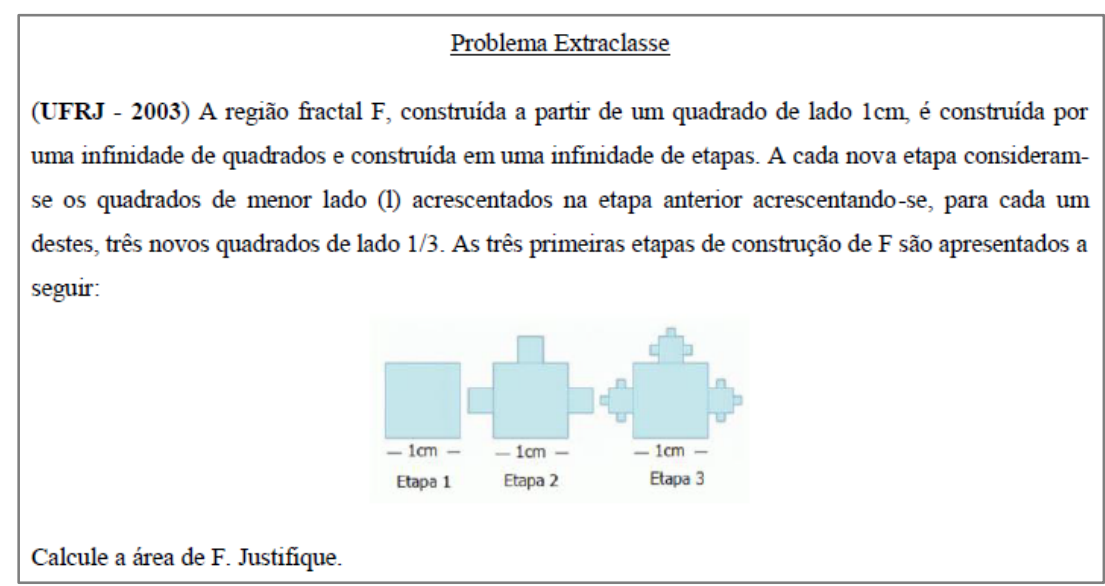

Figura 11: Problema Extraclasse do sétimo encontro (Acervo da Pesquisa)

Afirmamos que, dos três problemas referentes a esse encontro, este foi o que os grupos — estavam presentes nesta aula Baraka, Fermat, Joaquim e Joana - tiveram mais facilidade para resolver, uma vez que, segundo alguns deles, já haviam trabalhado com algo semelhante na disciplina de Recursos Tecnológicos II, que após mudanças na matriz curricular do curso, em 2019, passou a adotar o nome de Tecnologias no Ensino de Matemática.

Como podemos evidenciar na Figura 12, os grupos optaram por estratégias bem similares, para as quais escolheram por trabalhar com as ideias de somatório de infinitas parcelas e soma infinita de uma Progressão Geométrica.

Assim, os grupos padronizaram uma sequência, na qual foi observado, por eles, que a área de $F$ tinha um comportamento vinculado à soma de uma P.G. infinita. Deste modo, os grupos 1 e 2 conjecturaram, respectivamente, as seguintes relações de somatório: $\sum_{k=0}^{+\infty}\left(\frac{1}{3}\right)^{k} \mathrm{e}$ $\sum_{i=1}^{n} 3^{i-1}\left(\frac{1}{3^{i-1}}\right)^{i}$. Acreditamos que esta diferença ocorreu por dois motivos.

0 primeiro foi 0 evento de 0 Grupo 2 não notar que a potência de base 3, anterior a multiplicação, é "anulada" ao realizar o somatório, enquanto o Grupo 1 percebeu essa relação. 0 segundo ponto que evidenciamos é o fato de os grupos adotarem pontos iniciais diferentes, o que originou, naturalmente, em relações somáticas díspares.

${ }^{5}$ Os problemas 1 e 2 trabalhavam nessa perspectiva. 


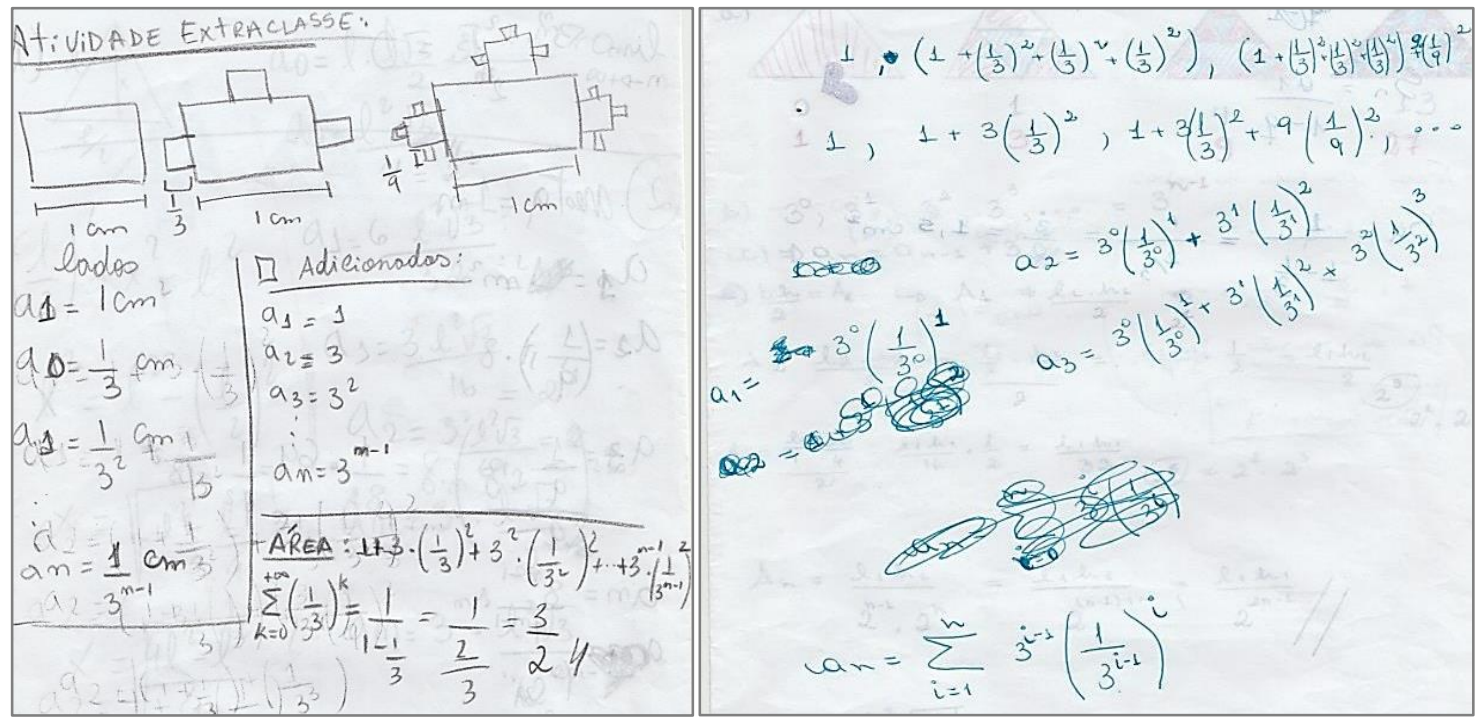

Figura 12: Resoluções dos grupos (Dados da pesquisa)

Nesse contexto observamos que para resolver seus somatórios, ambos os grupos optaram por utilizar o conceito de Soma Infinita da P.G. (Figura 13), visto no quinto encontro, a fim de definir a área de $F$. Concluindo, assim, que ela possui $\frac{3}{2} \mathrm{~cm}^{2}$ ou $1,5 \mathrm{~cm}^{2}$.

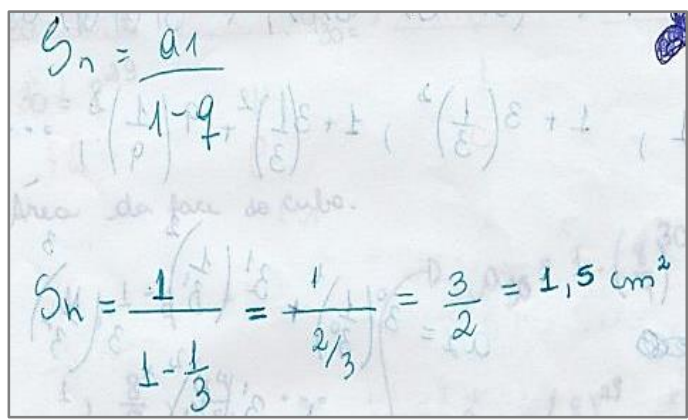

Figura 13: Resolução final do Grupo 2 (Acervo da Pesquisa)

Com base nos encontros e nos instrumentos de coletas de dados, elencamos três linhas de análise: (1) Os conceitos antecedentes como um agente desencadeador na aprendizagem de novos conhecimentos na MEAAMRP; (2) O trabalho colaborativo e cooperativo na construção do conhecimento profissional de licenciandos em Matemática da UFSM; e (3) Reflexões sobre a MEAAMRP no ensino da Progressão Geométrica.

No que se refere ao primeiro item ressaltamos que, apesar da MEAAMRP sugerir a construção da aprendizagem de um novo conteúdo sem a necessidade de utilizar fórmulas e/ou teoremas previamente estudados, os licenciandos em Matemática, sujeitos da pesquisa, ainda estavam afixados nessa concepção.

Acreditamos que isso tenha ocorrido porque, em geral, algumas disciplinas da Licenciatura 
em Matemática da UFSM fomentam um trabalho estabelecido em resolver questões por meio de fórmulas, teoremas e/ou axiomas já prontos. $E$, ainda, por muitas vezes não possibilitarem, ao aluno, desenvolver sua aptidão de raciocínio lógico a fim de compor relações com o objetivo de construí-las, sem a necessidade de decorá-las.

Cabe ressaltar também que, em determinados encontros, os conceitos antecedentes foram os responsáveis pelo desencadeamento de soluções e debates durante o processo de resolução dos problemas e da plenária. Como, por exemplo, ao nos referirmos ao Problema 1 do quinto encontro, que tinha por intuito trabalhar com os alunos o conceito de Soma Infinita de uma Progressão Geométrica no qual os grupos solucionaram-no de forma bem similar. No entanto, durante a plenária, foi levantada a necessidade de um conceito antecessor para a sua resolução e que foi identificado apenas por um dos grupos.

Conforme observado na Figura 9, o problema requeria saber o comprimento de uma espiral que era definido pela junção de comprimentos de infinitos semicírculos. Entretanto apenas o Grupo 1 fez essa analogia para resolvê-lo.

Percebemos que o Grupo 2 não definiu o comprimento da espiral por meio da soma dos valores dos infinitos semicírculos, conhecimento prévio necessário, para o qual eles somente balizaram a soma dos valores de todos os raios, sendo que não era isso que o problema requeria.

Quanto à segunda linha, evidenciamos que o trabalho cooperativo e colaborativo é uma peça essencial dentro da MEAAMRP, pois há a necessidade de um trabalho em grupo. 0 intercâmbio de saberes entre aluno-aluno e aluno-professor, que podem até ser discordantes, é primordial para a construção de um processo ensino-aprendizagem do conteúdo pretendido. Como ressalta Freire (1996, p. 25), "quem ensina aprende ensinando, e quem aprende ensina ao aprender".

Nesse contexto realçamos, por meio da nossa pesquisa, que isso vem ocorrendo ainda a passos lentos, principalmente no ensino de Matemática, no qual os alunos são, muitas vezes, condicionados a pensarem individualmente sem uma troca de informações e diálogos.

Nos primeiros encontros, por ainda estarem se adaptando às dez etapas da MEAAMRP sugeridas por Allevato e Onuchic (2014), apesar da disciplina seguir nessa ótica, era perceptível a insatisfação dos alunos ao trabalhar em grupo. Dessa forma, o trabalho cooperativo e colaborativo levou certo tempo para acontecer, sendo que nos últimos encontros este fluiu mais tranquilamente. 
No que se refere ao terceiro item — reflexões sobre a MEAAMRP no ensino da P.G. destacamos que Joaquim, no questionário final, afirmou que pôde cooperar pouco no trabalho em grupo, uma vez que os membros dos grupos em que participou já possuíam conhecimentos prévios sobre a P.G., incluindo suas fórmulas, e trabalhavam nessa perspectiva para as resoluções dos problemas, o que não era comum para ele já que não havia estudado esse conteúdo nem no Ensino Médio tampouco Superior.

No entanto, com o passar das aulas, Joaquim conseguiu estabelecer conexões que permitiram que suas contribuições fossem mais perspicazes e precisas que nos encontros anteriores, possibilitando assim uma melhor compreensão, de sua parte, dos fundamentos da P.G., uma vez que muitos conceitos eram desconhecidos por ele.

Por meio de algumas respostas, dadas no questionário final, pudemos averiguar que os alunos perceberam o quão relevante essa metodologia é no processo ensino-aprendizagem dos alunos nas aulas de Matemática e assim, quem sabe, futuramente poderão utilizá-la na suas práticas escolares, corroborando com o olhar, que foi evidenciado anteriormente, de Ferreira, Silva e Martins (2017, p. 215).

O aluno Fermat ressaltou, também no questionário final, que "[...] creio que para aplicar alguns exercícios vistos de P.G. no ensino público, talvez não seja bem aceito, devido à realidade de algumas escolas que apenas querem "passar" os alunos". Sabemos dos inúmeros contratempos que a MEAAMRP pode apresentar no Ensino Básico para alunos e professores não habituados com aulas nesta perspectiva. Além disso, consideramos que as aulas de Matemática devam ter metodologias diversas durante 0 ano letivo, lembrando que o que deve permanecer para o aluno é a postura de questionar os conteúdos e, para o professor, a postura de facilitador da aprendizagem.

Neste olhar, avigoramos que devemos desenvolver a MEAAMRP nas aulas de Matemática com a finalidade de mostrar para os alunos novas abordagens metodológicas de ensino, possibilitando, assim, que eles aprimorem seu nível de raciocínio lógico e criticidade ao resolver um problema, indo ao encontro do que é apontado por Pironel e Vallilo (2017).

Por fim, perguntamos quais às contribuições a MEAAMRP lhes proporcionou no seu ensino e aprendizagem referente à Progressão Geométrica. Destacamos a seguir algumas de suas respostas. 
Pra mim foram diversas contribuições, mas a principal: me ensinou a resolver problemas com Progressões Geométricas. (Joaquim).

Me ajudou muito, pois eu particularmente tinha certa dificuldade em resolver problemas com progressões, mas por ser um método de colaboração tive colegas que me ajudaram. (Baraka).

Uma melhor compreensão do assunto, porque até então tinha algumas lacunas na aprendizagem, tais como as relações existentes entre os termos de um PG, soma dos termos de uma PG infinita e PG de segunda ordem. (Joana).

Diante de todos esses apontamentos, aferimos que a MEAAMRP contribuiu satisfatoriamente no processo de ensino, aprendizagem e avaliação dos sujeitos dessa pesquisa. Proporcionando, a eles, um melhor entendimento dos conceitos referentes à P.G., para os quais alguns deles ainda possuiam pendências ou até mesmo não o conheciam como o caso de Joaquim.

\section{Exposições Finais}

Com base no desenvolvimento da pesquisa, podemos afirmar que, de maneira geral, alcançamos o objetivo pretendido para os encontros, já que pudemos identificar, no decorrer da pesquisa, certo avanço no aprendizado dos alunos com relação à Progressão Geométrica e ao trabalho cooperativo e colaborativo.

Na maioria dos encontros foi evidente como essa aprendizagem foi se encadeando no decorrer das aulas, onde para resolver um problema de determinado assunto, utilizavam de artifícios e/ou conhecimentos vistos em encontros passados, o que nos mostra que a MEAAMRP contribuiu significativamente ao seu ensino da Progressão Geométrica.

Cabe ressaltar que durante o quarto encontro o aluno Joaquim relatou que estava "adorando" a forma com que a P.G., conteúdo inédito para ele uma vez que não havia estudado nem no Ensino Médio e nem no Ensino Superior - havia desistido da disciplina de Matemática Discreta -, estava sendo abordada na disciplina, e segundo ele, sua compreensão estava muito clara o que lhe ajudaria no decorrer da graduação e na sua futura prática docente.

Ainda nesta perspectiva, ao ser perguntado, no questionário final, se a pesquisa contribuiu na sua formação acadêmica Joaquim assertiva:

"[...] gostaria, inclusive que tivesse uma segunda etapa da disciplina. Porque em uma única cadeira nos foi permitido estudar várias áreas da matemática, além disso, a cadeira possibilita a prática do raciocínio, não sendo necessário utilizar fórmulas 
prontas. A formalização dos exercícios foi muito importante também para estudar em casa um problema que na aula, pode ter me deixado em dúvida".

Realçamos também que, na pesquisa, nem tudo aconteceu como o planejamento prévio. Como por exemplo, em grande parte dos encontros os alunos não conseguiram desenvolver um trabalho colaborativo e cooperativo dentro dos seus grupos, papel fundamental na Metodologia de Ensino-Aprendizagem-Avaliação de Matemática através da Resolução de Problemas.

Isso pode ter ocorrido pelo fato deles não terem adquirido o hábito de trabalhar em grupos na escola, como evidenciado por alguns deles no questionário final, assim como pelo fato de que, de forma geral, as disciplinas da ementa da Licenciatura em Matemática fomentam um trabalho individual sendo o trabalho em grupo muitas vezes raro, principalmente naquelas voltadas para os conteúdos de Matemática, o que acarreta numa dificuldade dos licenciandos em trabalhar com pessoas que possuem outros pensamentos e/ou visões.

O trabalho com a Metodologia de Ensino-Aprendizagem-Avaliação de Matemática através da Resolução de Problemas necessita de muita dedicação por parte do professor (antes, durante e depois), uma vez que desde a escolha do problema gerador até a realização da plenária precisase de um encadeamento metodológico e de um planejamento muito bem estruturados, pois ela ocupa certo tempo da disciplina, que por muitas vezes, os professores não dispõem, como assinalado anteriormente.

Inclusive, alertamos que, a mudança de postura perante o aluno requer prática, uma vez que os professores, em especifico de Matemática, estão bem habituados em responder os questionamentos dos alunos, nas atividades, problemas e/ou questões, induzindo-os a perceber o que necessita para resolvê-los, muitas vezes de maneira assertiva. Todavia, nesta metodologia, esta atitude precisa ser invertida para que o próprio aluno deva descobrir, por meio de questionamentos do professor, as estratégias necessárias para solucionar a atividade, problema e/ou questão.

Acreditamos que esses fatores tenham modificado tanto a prática profissional dos pesquisadores como dos alunos uma vez que ambos, com exceção da segunda autora, não estavam acostumados a trabalhar o ensino de Matemática nessa perspectiva. Cabe destacar que, em certos momentos, apresentamos algumas dificuldades em seguir as etapas da Metodologia de Ensino-Aprendizagem-Avaliação de Matemática através da Resolução de Problemas, no entanto elas sempre foram respeitas, por mais adverso que tenha sido o encontro. 
Alguns planejamentos iniciais dos encontros também precisaram sofrer modificações durante o desenvolvimento das atividades. Vale, então, ressaltar que o professor ao utilizar essa metodologia precisa estar ciente que ela, de certa maneira, é imprevisível. Poderão ocorrer encontros nos quais os alunos não manifestarão interesse em trabalhar com o(s) problema(s) planejado(s) para aquela aula, por motivos distintos, ou, ainda, não conseguirão desenvolver estratégias para resolvê-lo(s), E assim a metodologia não proporcionará o efeito desejado pelo professor para aquele dia.

Dessa forma, a partir desta investigação, o emprego dessa metodologia revelou-se como uma possível abordagem a ser utilizada por alunos e professores que procuram por estratégias de ensino, aprendizagem e avaliação para a Matemática, em específico da Progressão Geométrica sem a necessidade da memorização de fórmulas e teoremas prontos, mas sim da possibilidade da construção delas, em conjunto, num trabalho colaborativo e cooperativo. E ainda, ressaltamos que precisa-se dar mais voz aos alunos deixando que participem das atividades de sala de aula, oportunizando a formação crítica de cidadãos, além de bons resolvedores de problemas de Matemática. Para pesquisas futuras sugerimos averiguar como os problemas desse artigo se comportam no ensino-aprendizagem-avaliação, da P.G., com os alunos do Ensino Médio.

\section{Referências}

ALLEVATO, Norma Suely Gomes; ONUCHIC, Lourdes de La Rosa. Ensino-AprendizagemAvaliação de Matemática: por que através da Resolução de Problemas? In: ONUCHIC, Lourdes de La Rosa; ALLEVATO, Norma Suely Gomes; NOGUTI, Fabiane Cristina Höpner; JUSTULIN, Andresa Maria. (Org.). Resolução de Problemas: teoria e prática. Jundiaí: Paco Editorial, 2014. p. $35-52$.

BORBA, Marcelo de Carvalho; ALMEIDA, Helber Rangel Formiga Leite de; GRACIAS, Telma Aparecida de Souza. Pesquisa em ensino e sala de aula: diferentes vozes em uma investigação. Belo Horizonte: Autêntica. 2018.

CORREA, Matheus Metz. Uma proposta didática para o ensino de sequências através da metodologia da resolução de problemas com o auxílio das questões da OBMEP. 2016. Trabalho de Conclusão de Curso (Licenciatura em Matemática) - Centro de Ciências Naturais e Exatas. Universidade Federal de Santa Maria. Santa Maria.

CORREA, Matheus Metz; NOGUTI, Fabiane Cristina Höpner. Um mapeamento sobre dissertações e teses da região Sul na perspectiva da Resolução de Problemas para o ensino de Matemática. In: ENCONTRO BAIANO DE EDUCAÇÃO MATEMÁTICA, 18, 2019, Ilhéus. Anais do XVIII EBEM: a sala de aula de Matemática e suas vertentes. Ilhéus: SBEM-BA/UESC, 2019, p. 1-5. 
FERREIRA, Nilton Cezar; SILVA, Lilian Esquinelato da.; MARTINS, Egidio Rodrigues. Resolução de Problemas no Ensino Superior. In: ONUCHIC, Lourdes de La Rosa; LEAL JUNIOR, Luiz Carlos; PIRONEL, Márcio. (Org.). Perspectivas para Resolução de Problemas. São Paulo: Livraria da Física, 2017, p. 189-219.

FIORENTINI, Dario; OLIVEIRA, Ana Teresa de Carvalho Correa de. O lugar das matemáticas na Licenciatura em Matemática: que matemáticas e que práticas formativas? Bolema, Rio Claro, v. 27, n. 47, p. 917-938, dez. 2013.

FREIRE, Paulo. Pedagogia do oprimido: saberes necessários à prática educativa. 25 ed. São Paulo: Paz e Terra, 1996.

KRULIK, Stephen; REYS, Robert. A resolução de problemas na Matemática escolar. Tradução de Hygino Hugueros Domingues e Olga Corbo. São Paulo: Atual, 1997.

LÜDKE, Menga; ANDRÉ, Marli Eliza Dalmazo Afonso de. Pesquisa em educação: abordagens qualitativas. 2 ed. São Paulo: EPU, 2015.

MORAIS, Rosilda dos Santos; ONUCHIC, Lourdes de La Rosa. Uma abordagem histórica da Resolução de Problemas. In: ONUCHIC, Lourdes de La Rosa; ALLEVATO, Norma Suely Gomes; NOGUTI, Fabiane Cristina Höpner; JUSTULIN, Andresa Maria. (Org.). Resolução de Problemas: teoria e prática. Jundiaí: Paco Editorial, 2014, p. 17-34.

ONUCHIC, Lourdes de La Rosa; ALLEVATO, Norma Suely Gomes. Pesquisa em Resolução de Problemas: caminhos, avanços e novas perspectivas. Bolema, Rio Claro, v. 25, n. 41, p. 73-98, dez. 2011.

ONUCHIC, Lourdes de La Rosa; NOGUTI, Fabiane Cristina Höpner. A pesquisa científica e a pesquisa pedagógica. In: ONUCHIC, Lourdes de La Rosa; ALLEVATO, Norma Suely Gomes; NOGUTI, Fabiane Cristina Höpner; JUSTULIN, Andresa Maria. (Org.). Resolução de Problemas: teoria e prática. Jundiaí: Paco Editorial, 2014, p. 53-68.

PIRONEL, Márcio; VALLILO, Sabrina Aparecida Martins. O papel da avaliação na Metodologia de Ensino-Aprendizagem-Avaliação de Matemática através da Resolução de Problemas. In: ONUCHIC, Lourdes de La Rosa; LEAL JUNIOR, Luiz Carlos; PIRONEL, Márcio. (Org.). Perspectivas para Resolução de Problemas. São Paulo: Livraria da Física, 2017, p. 279-304.

POLYA, George. A arte de resolver problemas. Tradução de Heitor Lisboa de Araújo. Rio de Janeiro: Interciência, 1995.

PROENÇA, Marcelo Carlos de. Resolução de Problemas: encaminhamentos para o ensino e aprendizagem de Matemática em sala de aula. Maringá: EdUEM, 2018.

SCHROEDER, Thomas L; LESTER JR., Frank K. Developing understanding in Mathematics via Problem Solving. In: TRAFTON, Paul R.; SHULTE, Albert P. (Ed.) New directions for elementary school Mathematics. Reston: NCTM, 1989, p. 31-42.

YIN, Robert K. Estudo de caso: planejamento e métodos. 2 ed. Tradução de Daniel Grassi. Porto Alegre: Bookman, 2001. 